\title{
Study of optical and structural properties of prepared gold nanoparticles by pulse laser ablation method
}

\author{
Noor Mohammad Ali Fadhil Jihad ${ }^{1 *}$, Fathi Mohammad Jasim² \\ $1 *$ Department of Physics, College of Education for Pure Sciences, University of Mosul, Mosul, Iraq. \\ ${ }^{2}$ Department of Physics, College of Education for Pure Sciences, University of Mosul, Mosul, Iraq. \\ E-mail: ${ }^{1 *}$ noor.esp124@ student.unmosul.edu.iq, ${ }^{2}$ phyfathe1@uomosul.edu.iq
}

(Received March 11, 2021; Accepted May 06, 2021; Available online September 01, 2021)

DOI: 10.33899/edusj.2021.129702.1148, (C) 2021, College of Education for Pure Science, University of Mosul.

This is an open access article under the CC BY 4.0 license (http://creativecommons.org/licenses/by/4.0/).

\begin{abstract}
In this paper, the ablation of pure gold target in distilled water (DW) using Nd:YAG laser of wavelength $1064 \mathrm{~nm}$ and different laser energies $(480,680,880) \mathrm{mj}$, with repetition frequency of $6 \mathrm{~Hz}$ and number of pulses 300 pulse were studied. The optical properties were studied by UV-VIS spectroscopy, and the spectra showed the appearance of sharp peaks as a result of the plasmonic absorption surface at $(532,531,529) \mathrm{nm}$ corresponding to the above mentioned energies. The results of the atomic force microscope (AFM) test also showed that the average size of gold nanoparticles decreases with the increase of the energy of the pulsed laser, that gold nanoparticles possess a cube crystalline phase (FCC) according to X-ray diffraction (XRD) test whereas the results of the scanning electron microscope (SEM) showed that the gold nanoparticles have an almost spherical shape.

Laser skimming of solids in liquid has opened up unique prospects for the manufacture of nanostructures and as a result there has been rapid growth of studies in the composition of nanostructures by this new technology in recent years. The resulting nanoparticles are somewhat crystallized, and can be obtained in an easy and one-step way without any subsequent heat treatment. Due to the high potency of the cut-off parts, pure colloidal solutions of nanoparticles can form a product that accumulates in the colloidal solution obtained in a very easy way. Colloidal gold is very attractive to many applications in biotechnology and biomedicine because of its unique physical and chemical properties.
\end{abstract}

Keywords: Pulsed laser ablation, Gold nanoparticles, Surface plasmon resonance (SPR), Optical properties.

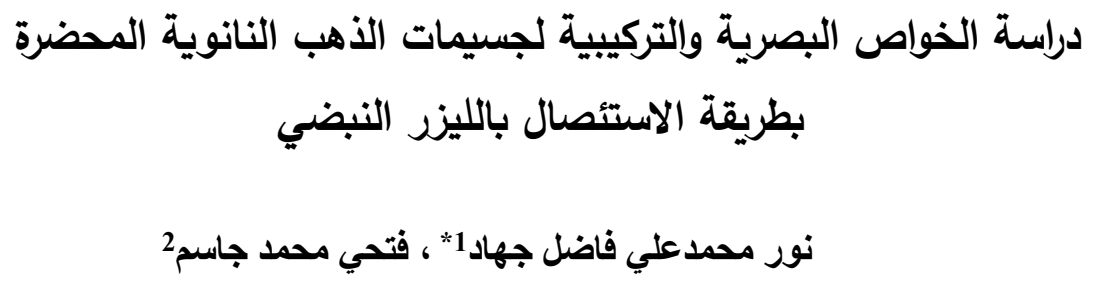




\section{Journal of Education and Science (ISSN 1812-125X), Vol: 30, No: 4, 2021 (69-82)}

1*2*2 قسم الفيزياء، كلية التربية للعلوم الصرفة، جامعة الموصل ، الموصل، العراق.

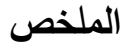

أجري في هذا البحث استئصال لهذف معدني من الذهب النقي في الماء المقطر (DW) باستخدام ليزر النديميوم ياك ذو طول

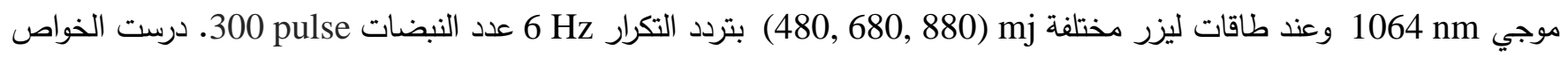
البصرية بططيافية الاشعة فوق البنفجية (UV-VIS) وبينت الاطياف ظهور ذروات حادة نتيجة الامتصاص السطحي البلازموني عند (532, 531, 529) nm المقابلة للطاقات المذكورة اعلاه. كما اظهرت نتائج فحص مجهر القوة الذرية (AFM) ان معدل حجم جسيمات الذهب النانوية يتناقص بزيادة طاقة الليزر النبضي، وان جسيمات الذهب النانوية تمتلك طورا بلوريا مكعباً (FCC) وفقاً لنتائج حيود الأشعة السينية (XRD) في حين أن نتائج فحص المجهر الاككتروني الماسح (SEM) اظهرت ان لجسيمات الذهب النانوية شكلا كرويآ تقريباً.

القشط الليزري للمواد الصلبة في السائل فتحت آفاقآ فريدة من نوعها لتصنيع التراكيب النانوية وكنتيجة لهذا كان هناك نمو سريع للدراسات في تكوين التراكيب النانوية بواسطة هذه التقنية الجديدة في السنوات الأخيرة. تكون الجسيمات النانوية الناتجة متبلورة إلى حد ما, ويمكن الحصول عليها بطريقة سهلة وبخطوة واحدة بدون أي معالجة حرارية لاحقة بسبب الفعالية العالية للأجزاء المقشوطة, يمكن أن تشكل المحاليل الغروية النقية للجسيمات النانوية منتجا يتجمع في المحلول الغروي الذي تم الحصول عليه بطريقة سهلة جدا. الذهب الغرواني جذاب للغاية للعديد من التطبيقات في مجال التكنولوجيا الحيوية والطب الحيوي بسبب خصائصه الفيزيائية والكيميائية الفريدة.

الكلمات الاالة: الاستئصال بالليزر النبضي، جسيمات الذهب النانوية، رنين البلازمون السطحي (SPR)، الخواص البصرية.

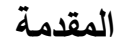

النانو هي كلمة يونانية تعني صغير الحجم، تصنف الجسيمات التي لها بعدان أو أكثر في نطاق الحجم -1) nm (100 على أنها جسيمات نانوية حسب مواصفات الجمعية الامريكية لإختبار المواد (ASTM) [1]. إن تواجُد المواد في قياس النانو يكسبها عدة مميزات

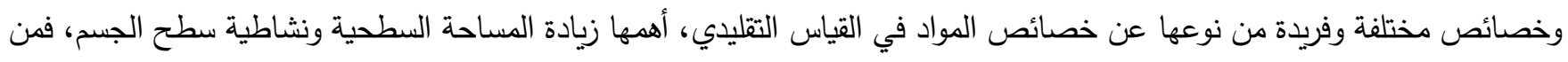
المعروف أن تصغير قياس جسمٍ ما سيؤدي إلى ميله للتأثر بسلوك الوحدات الأساسية المكونة لذلك الجسم( الذرات والجزيئات)، وبالتالي

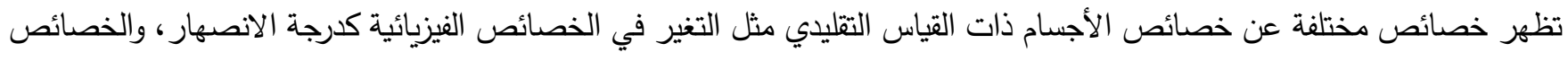
النوعية كثابت العزل، وتحدُث تغيرّات في النشاطية والذوبانية وجميع الخصائص المتعلقة بالكتلة وانتقال الحرارة، وتسمى التغيُرات في في

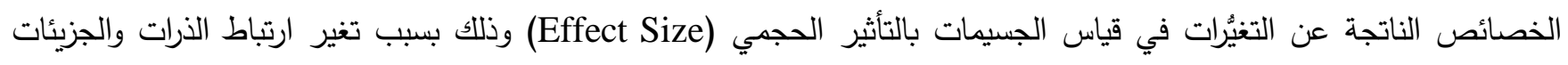
المكوِنة لتلك الأجسام .كما أن الذرات والجزيئات الموجودة على السطح تكون نشطة جدَّا، مما يُسهل ارتباطها بمواد أخرى، معطيةا بذلك خصائص مغايرة لخصائص الأجسام الكبيرة [2].

يُستخدم في تقنية النانو كغيرها من التقنيات عددُ من المصطلحات الخاصة منها علم النانو وهو العلم الذي يهتم بدراسة المبادئ الأساسية والخواص التركيبية للمواد في مقياس النانو وتعرف الجسيمات النانوية بأنها تجمُع ذري أو جزيئي يتراوح عددها من بضع (ذرات أو جزيئات) إلى مليون ذرة مرتبطة بعضها البعض بشكل كروي تقريباً له نصف قطر أقل من (100 nm) إن جسيمآ نانوياً نصف قطره نانومتر واحد سوف يحتوي على 25 ذرة، أغلبها على سطح الجسيم. وتؤدي أبعاد الجسيم النانوي لحدوث ظواهر فئينياتئية معينة، مثل تغيير 


\section{Journal of Education and Science (ISSN 1812-125X), Vol: 30, No: 4, 2021 (69-82)}

متوسط المسار الحر الذي تقطعه الإلكترونات بين تصادُمين متتالييَن مع الذرات المهتزة، وهذا يحدد التوصيلية الكهربية .كما أن الخواص

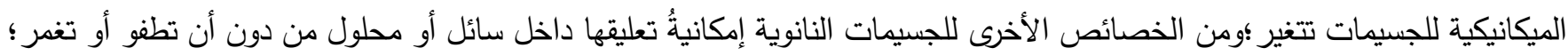

وذللك لأن التفاعل بين سطح الجسيمات والسائل يكون قويًّا بحيث يتغلب على فرق الكثافة بينهما [2]. تقسم تقنية تصنيع المواد النانوية إلى طريقتين أساسيتين : الأولى هي الانهيار من الأعلى إلى الأسفل (Top-down) ويتم ذلك فئك

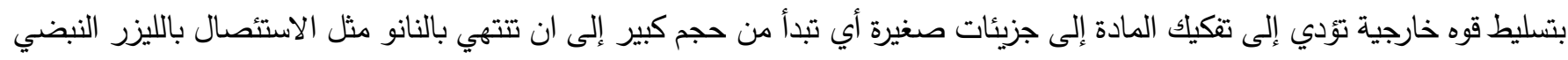

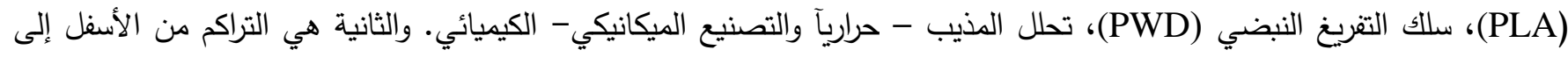
الأعلى(down-Top) وتبدأ من الذرات والجزيئات إلى إن يصل البناء إلى النانو مثل الترسيب بالليزر النبضي (PLD)، ترسيب البخار الكيميائي (CVD)، تقنية SOL-GEL، الترسيب الكهربائي [3, يمكن إنتاج الجسيمات النانوية عن طريق الاستئصال بالليزر قصير النبضة لهدف صلب في وسط سائل، توفر هذه الطريقة فرصة

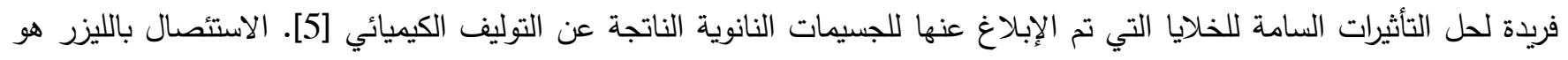
عملية إزالة مادة من سطح صلب أو سائل أحيانًا عن طريق تشعيعها باستخدام شعاع الليزر .عند استخدام طاقة ليزر عالية يتم تسخين المادة بواسطة طاقة الليزر التي يمتصها الهدف مما يتسبب في التبخر أو التسامي بسبب درجة الحرارة العالية. عندما تسقط طاقة الليزر العالية لوحدة الزمن على الهدف، تتحول المادة إلى بلازما. تستخدم عملية الاستئصال لإزالة المواد باستخدام الليزر النبضي حيث يعتمد معدل الاستئصال (كمية المادة التي يتم إزالتها بواسطة نبضة ليزر واحدة) على طاقة الليزر، عمق الاختراق، الخصائص البصرية للمادة

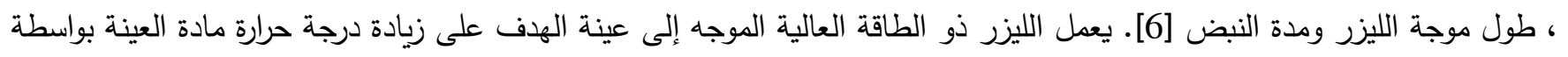
الطاقة الممتصة من الليزر، تصل درجات الحرارة إلى 20000 كلفن في هذه الاثناء تتشكل البلازما. يعمل المجال الكهربائي المرافق لنبضة علئه الليزر الكهرومغناطيسية على تعجيل الإكترونات الحرة إلى طاقة قياسية لتأين الذرات التي تصطدم بها، مما ينتج إلكترونات أخرى تساهم في التأين [7]. عند إنتهاء نبضة الليزر تبدأ عملية التبريد بتوسع البلازما بموجة صدمة في المقدمة. أثناء تبريد البلازما، لوحظ انبعاث

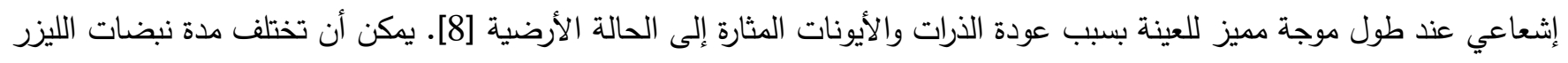

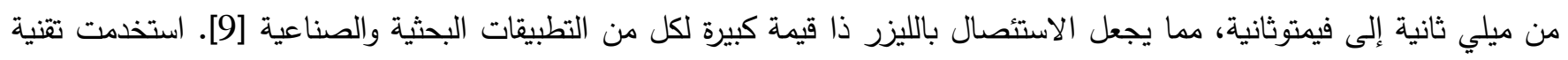

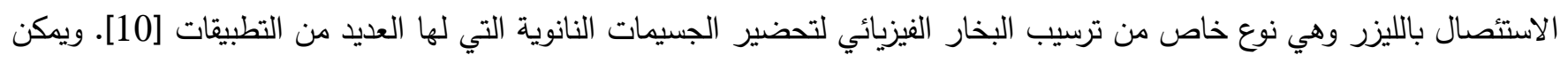

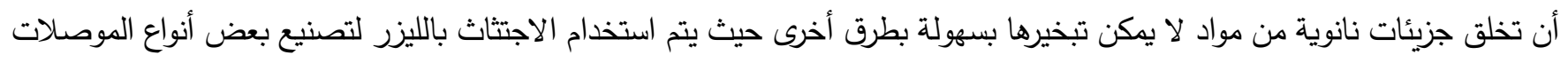

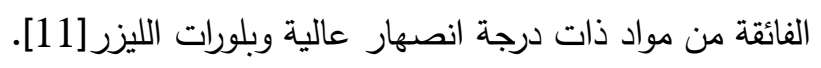
تمتلك جسيمات الذهب النانوية AuNPs خصائص بصرية فريدة في المنطقة المرئية بسبب تذبذب البلازمون السطحي للإلكترونات الحرة عند سقوط الضوء عليها [12]. Surfase Plasmon Resonance (SPR) وهو الرنين الذي يكمن في التردد المرئي للمعادن النبيلة مثل الفضة والذهب والنحاس، وهذه الخاصية هي المسؤولة عن تغيير الوان هذه العناصر عند وصولها لحجم النانو وتعتمد على حجم الجسيم وشكله والوسط الموجود فيه، تتسبب هذه الخاصية في رفع درجة حرارة الوسط المحيط بالجسيم النانوي عند سقوط الضوه عليه ولها خصائص وتطبيقات عدة منها [13]. قتل الخلايا السرطانية من خلال استخدام جسيمات الذهب. واستخدام جسيمات الذهب النانوية في صناعة كبسولات وفي داخلها دواء ولا تخرج هذه ما بداخلها من دواء الا عند سقوط اشعة الليزر عليها فتصهر البوليمر المتكون منه الكبسولة[13]. تُستخدم جسيمات الذهب النانوية بشكل شائع في نطاق واسع في مجال التكنولوجيا الحيوية والطب الحيوي، نظرًا لطبيعتها

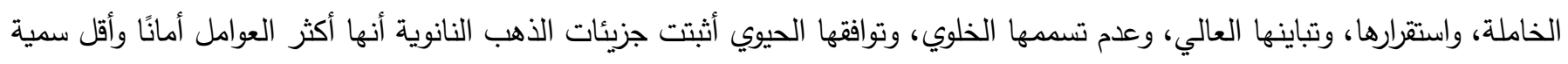
بكثير لتوصيل الأدوية (14) (14) delivery). 
تم تحضير جسيمات الذهب النانوية AuNPs عن طريق الاستئصال بالليزر النبضي(PLA) لقطعة ذهب ذات نقاوة عالية

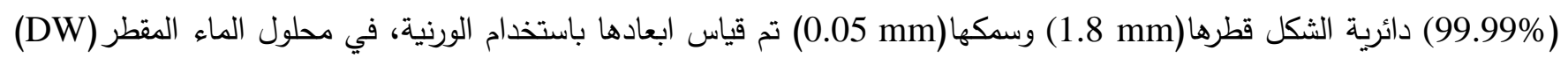

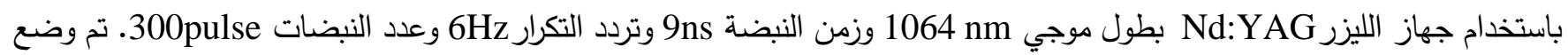
العينة في قاع وعاء ماء ويتم تركيز شعاع الليزر على سطح العينة باستخدام عدسة لامة من الكوارتز بعدها البؤري (9cm) توضع امام

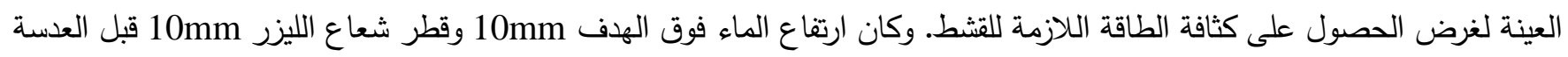
وحجم الماء في حاوية الاجتثاث 3ml وتم استئصال الهدف عند طاقات ليزر مختلفة (480, 680, 880). يستخدم الليزر النبضي Nd:YAG (عقيق الألومنيوم الأيتريوم المشبع بالنيوديميوم) في العديد من التطبيقات كمصدر للطاقة. إذ أن هذا النوع من الليزر هو الأكثر الأنواع شيوعًا من ليزر الحالة الصلبة ويستخدم على نطاق واسع لأنه موثوق به وسهل الاستخدام .

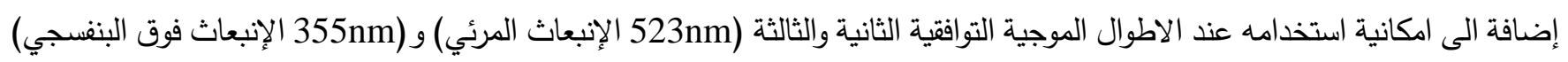
على التوالي. حيث يتم انشاء هذه التوافقيات عن طريق ادخال بلورة بصرية غير خطية في مسار اشعاع الليزر 1064 عالئه علاوة على

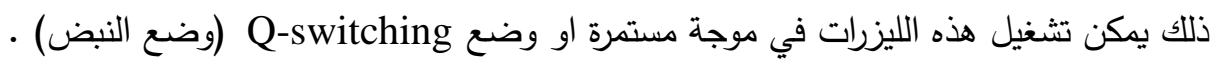
من الجدير بالذكر إن درجة حرارة جهاز الليزر يجب مراقبتها والتحكم فيها لكي لاتتجاوز درجة حرارة التشغيل 37 درجة مئوية وذلك من اجل الحفاظ على الجهاز بعيداً عن التلف والخلل في الوسط الفعال (بلورة YAG). ومن الضروري أيضا إعادة ضبط الليزر لتجهيزه للعمل مرة أخرى وذلك من خلال إعادة ضبط عداد النبض • يوضح الشكل 1 تفاصيل الجهاز المستخدم للاستئصال بالليزر • تم

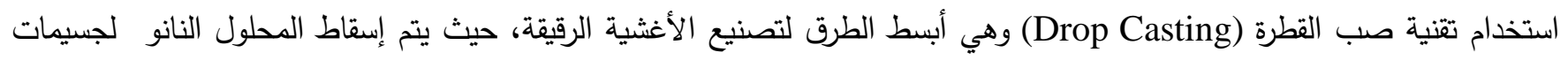
الذهب(AuNPs) عن طريق استخدام الماصة على قواعد زجاجية موضوعة بصورة أفقية بعد ان تمرر بعدة مراحل لضمان تتظيفها التام لما له من أهمية في تكوين مادة الغشاء المحضر ، وان وجود الثوائب يؤثر بصورة كبيرة على دقة القياسات الناتجة ، ثم يتم تعريضها لارجة حرارة 300 كلفن لكي تجف لغرض استخدامها في اجراء الفحوصات المطلوبة.

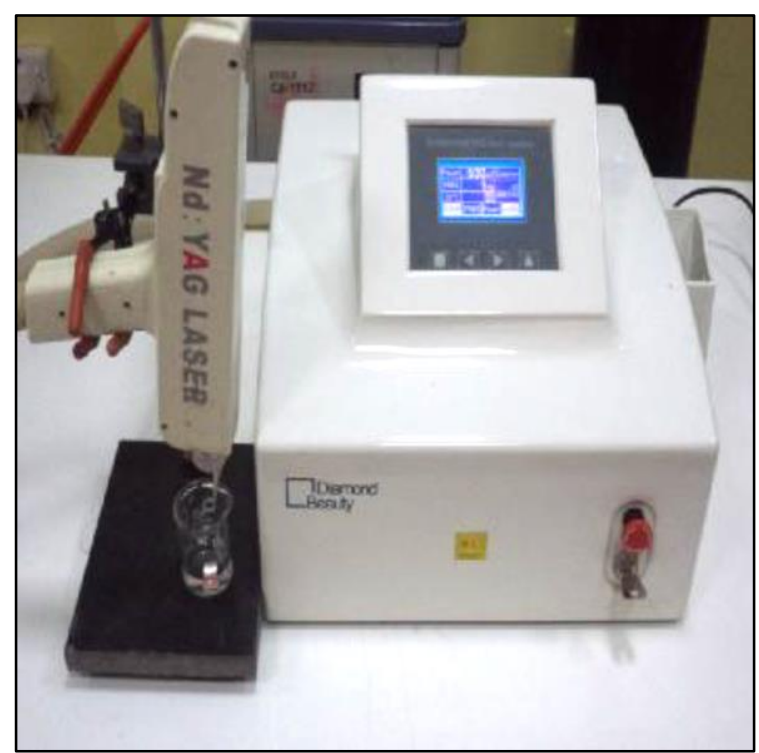

ب - الجهاز المستخدم للاستئصال بالليزر النبضي

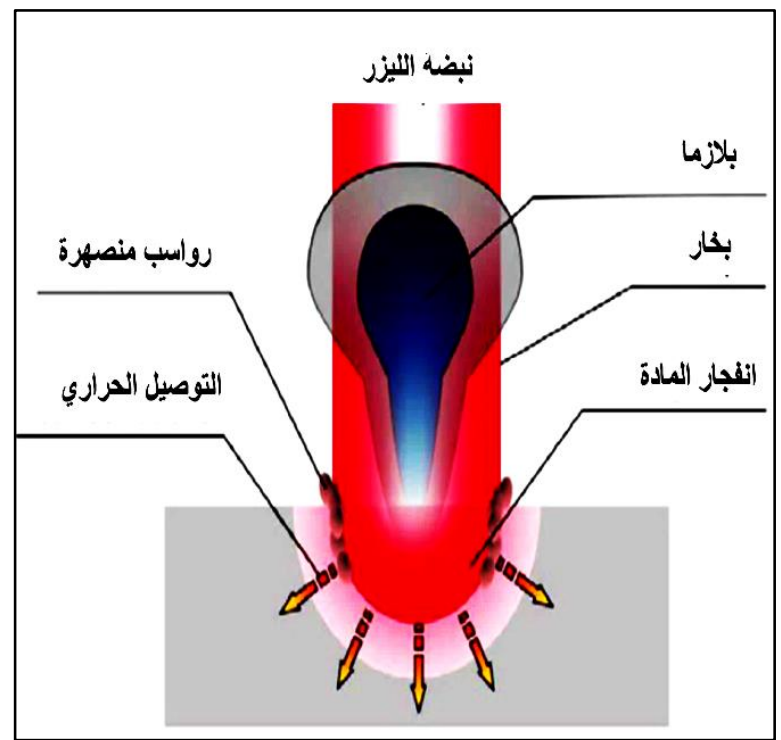

أ-تقنية الاستئصال بالليزر النبضي

الشكل 1. تفاصيل الجهاز المستخدم للاستئصال بالليزر . برل 


\section{النتائج والمناقثة \\ UV-Visible spectroscopy of AuNPs لجسيمات الذهب النانوية: ألتحليل الطيفي(UV-VIS)}

ان تحليل UV-Visible طريقة فعالة لدعرفة شكل وحجم الجسيمات النانوية، وتم فحص معلقات جسيمات الذهب النانوية المحضرة في الماء بواسطة الليزر النبضي Nd-YAG بطول موجي mm mi 1064 وطاقات ليزر (480, 680, 880) عن طريق الامتصاص المرئي للأشعة فوق البنفجية. يوضح الثكل 2 ان لون محلول AuNPs قد تغير مع زيادة طاقة الليزر بسبب زيادة تركيز الجسيمات النانوية المتولدة

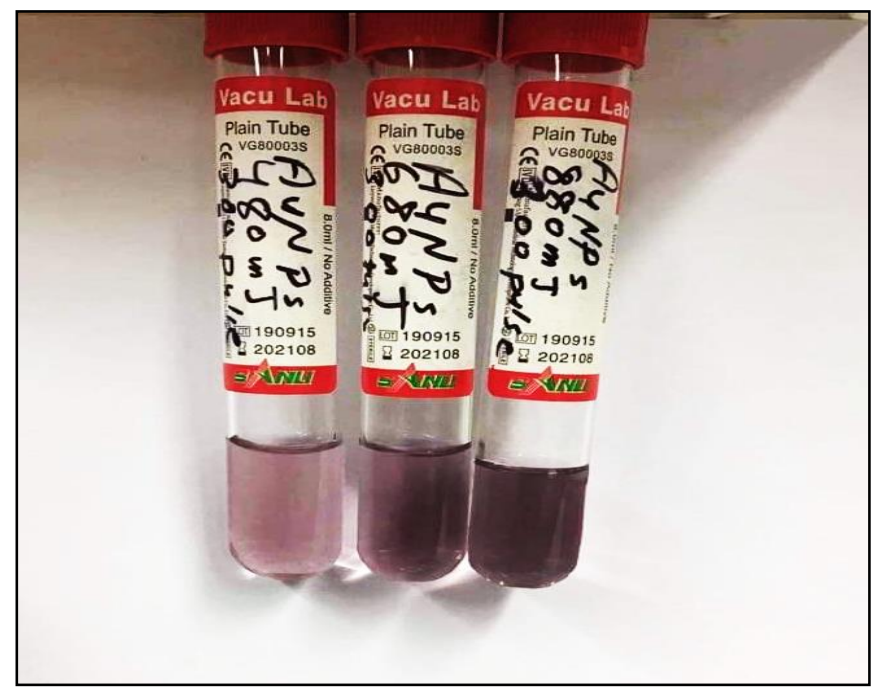

الثكل 2. عينات جسيمات الذهب النانوية المحضرة في الماء المقطر (DW).

Optical Properties الخصائص البصرية

عندما يتفاعل الضوء مع المادة يمكن تصنيف العمليات البصرية التي لوحظت في المواد الصلبة على أنها انعكاس وانكسار

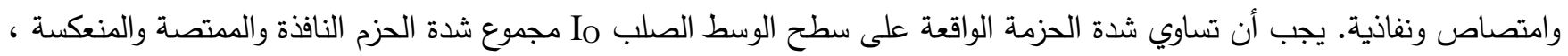

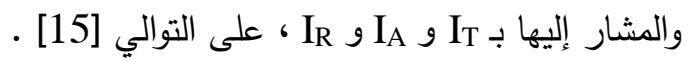

$\mathrm{I}_{\mathrm{O}}=\mathrm{I}_{\mathrm{T}}+\mathrm{I}_{\mathrm{A}}+\mathrm{I}_{\mathrm{R}}$

$\mathrm{T}+\mathrm{A}+\mathrm{R}=1$

Absorption spectrum 1

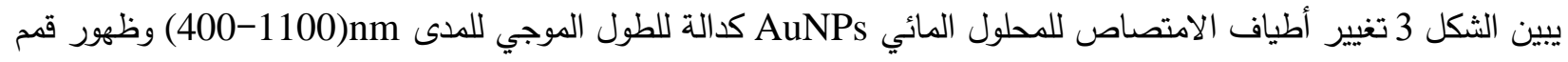
الذروة لرنين البلازمون السطحي Surface Plasmon Resonance) لجسيمات الذهب النانوية عند الاطوال الموجية

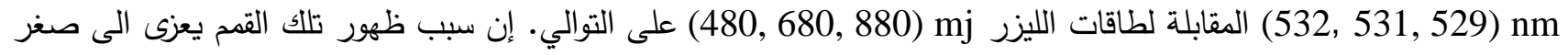

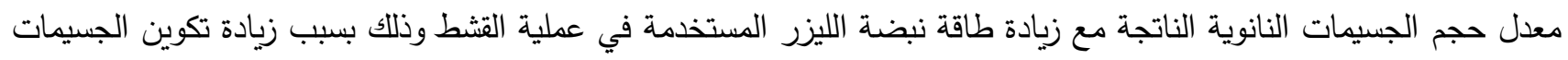

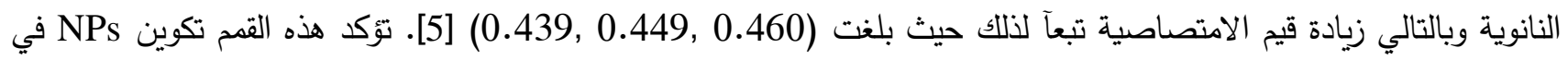


المحلول وان ظهور ذروة رنين البلازمون السطحي (SPR) مع زيادة طاقة الليزر كانت باتجاه الطول الموجي الأقصر (ازاحة زرقاء) وذللك يعود الى تشتت مي (Mie scattering) الذي يحدث عند سقوط موجة كهرومغناطيسية على جسيمات نانوية كروية والتي انصاف اقطارها مساوية للطول الموجي للضوء الساقط [16].

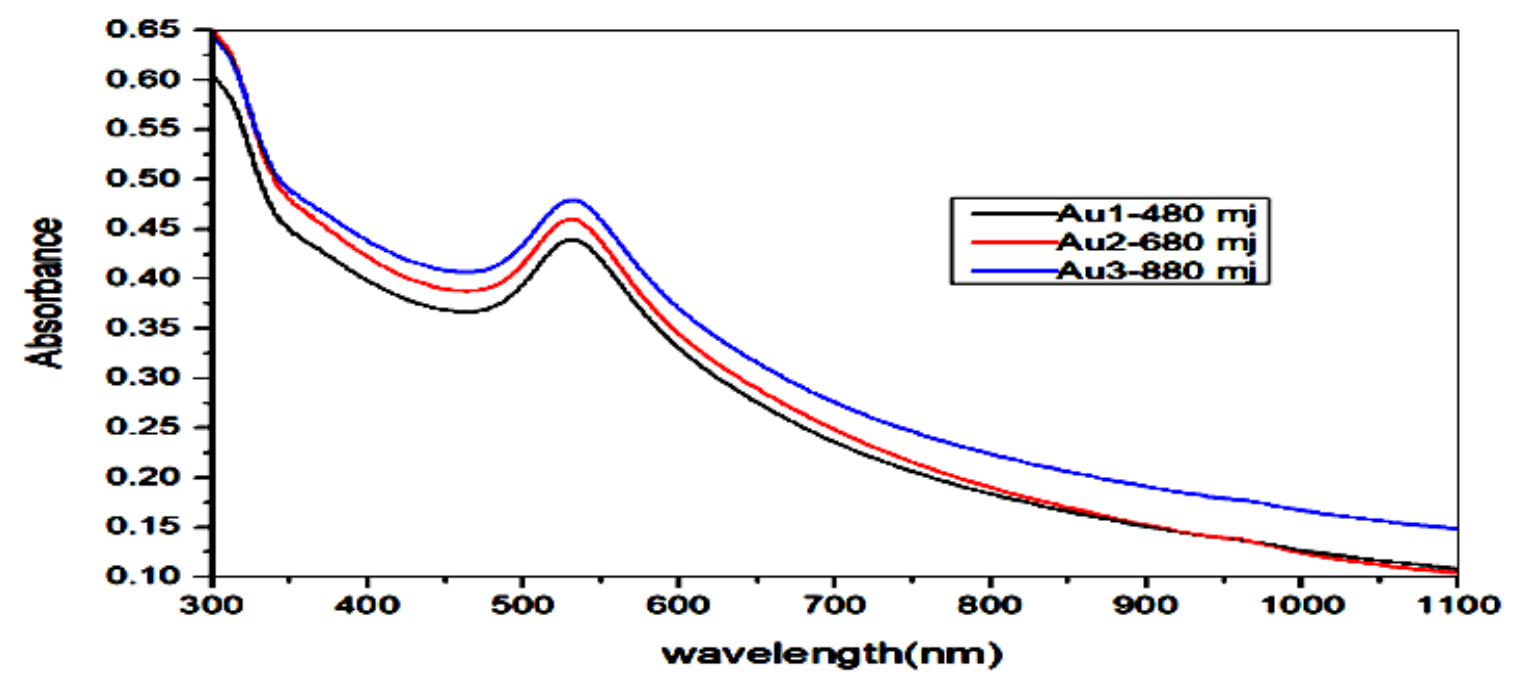

الثكل 3. طيف الامتصاصية كدالة للطول الموجي لجسيمات Au النانوية

المخرة عند طاقات ليزر نبضي مختلفة.

2- طيف النفاذية Transmittance spectrum

يوضح الثكل 4 تحليل طيف النفاذية AuNPs كدالة للطول الموجي والذي يكون معاكساً لطيف الامتصاص حيث ان النفاذية ازدادت كلما زاد الطول الموجي وتبلغ اعلى قيمة لها عند مدى الاطوال الموجية تحت الحمراء القريبة (خ أن النفاذية قد قلت عند زيادة طاقة نبضة الليزر ويعزى السبب في ذلك الى زيادة نسبة القشط الناتجة والتي تؤدي الى زيادة عدد الجسيمات الماصة لطاقة الاشعاع الكهرومغناطيسي مما يؤدي الى زيادة الامتصاصية وبالتالي يقلل من النفاذية [15].

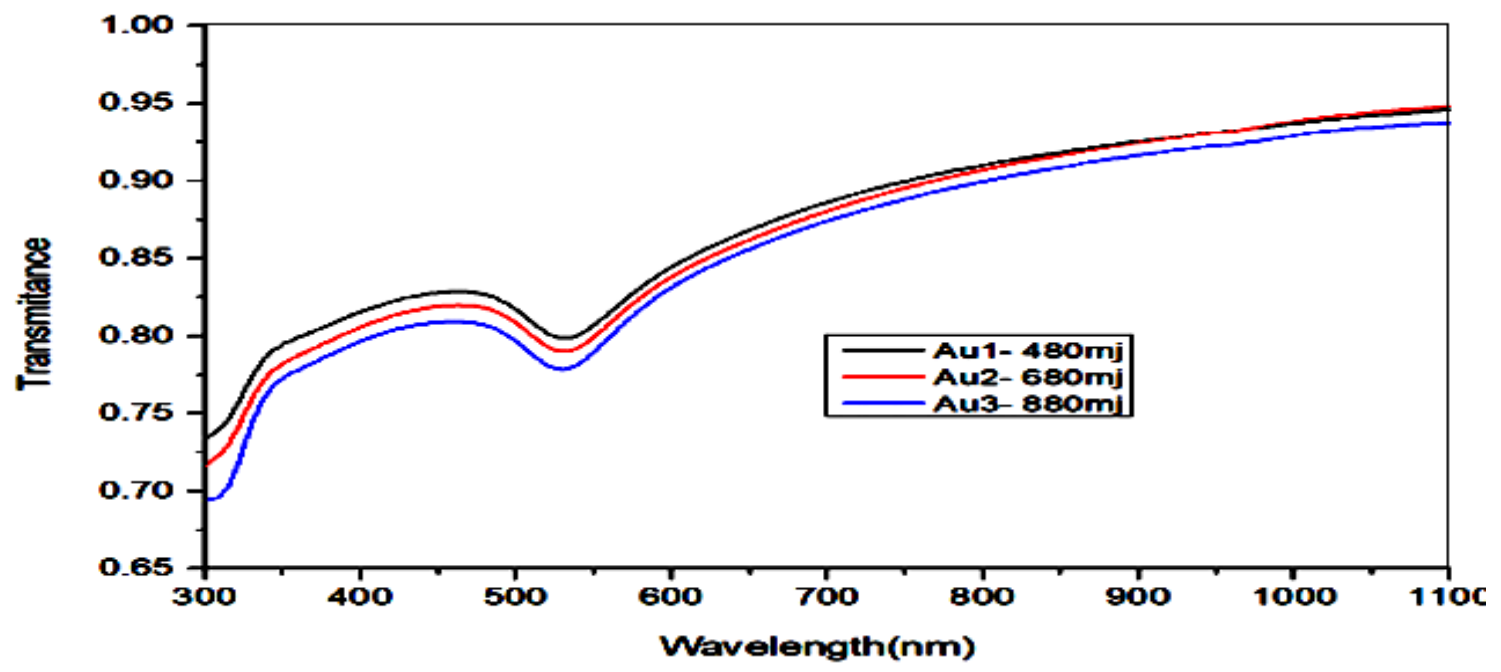

الشكل 4. يوضح طيف النفاذية كدالة للطول الموجي لجسيمات Au النانوية المحضرة عند طاقات ليزر نبضية مختلفة. 
تم حساب طيف الانعكاسية من خلال طيفي الامتصاصية والنفاذية وفق المعادلة (2). يوضح الشكل 5 اطياف انعكاس AuNPs كدالة للطول الموجي المحضرة في DW. نلاحظ أن ارتفاع ذروة الانعكاسية يزداد بزيادة طاقة نبضة الليزر في المناطق المرئية

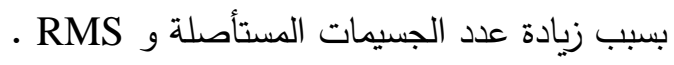

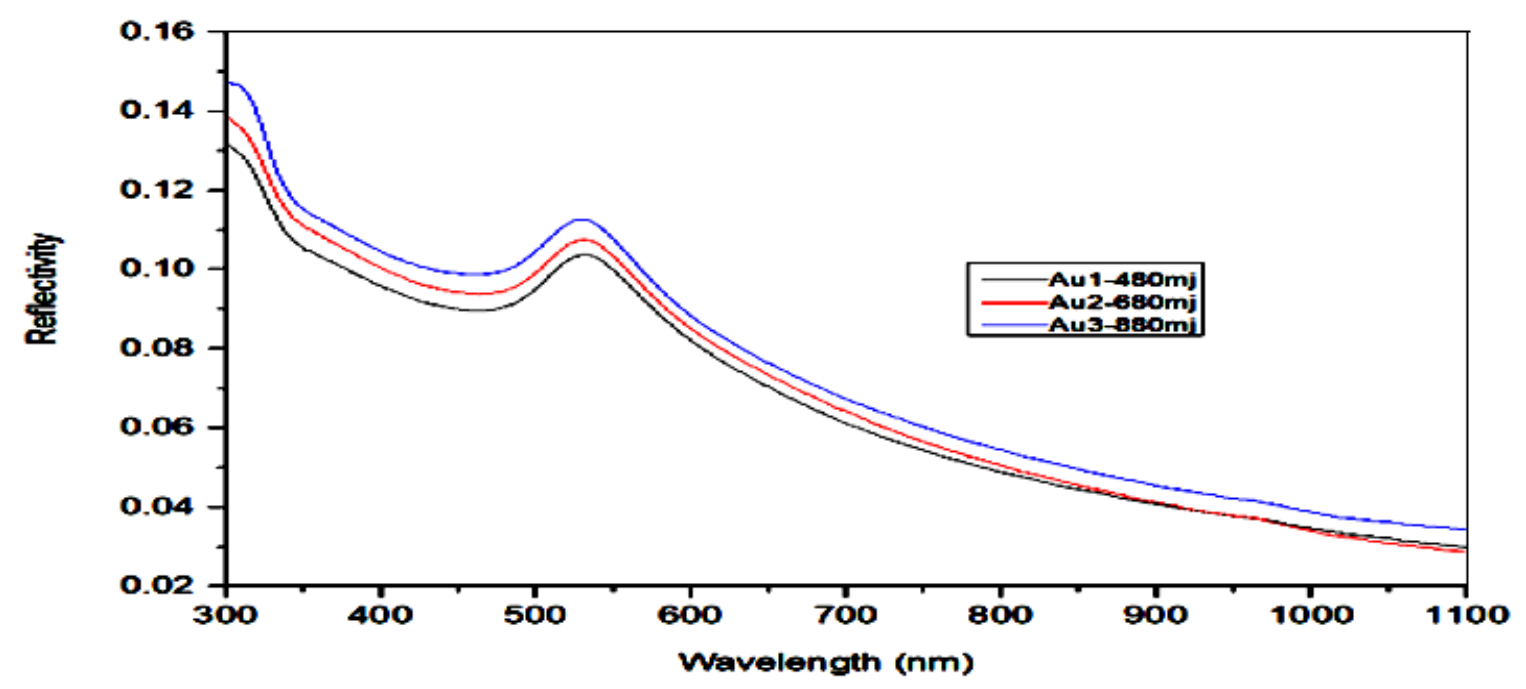

الثكل 5. يوضح طيف الانعكاسية كدالة للطول الموجي لجسيمات Au النانوية المحضرة عند طاقات ليزر نبضية مختلفة.

ثانيآ: فحص مجهر القوة الأرية Atomic Force Microscope (AFM)

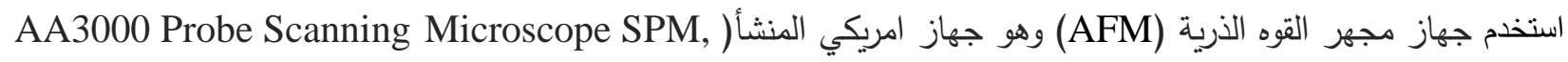
tip NsC35/AIBS ). ويعتبر هذا الميكروسكوب الأكثر شهرة كأداة تكبير وقياس تحريك على المستوى النانوي. تم استخدم الجهاز

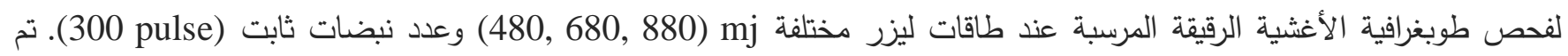
التعرف على معدل الخشونة والحجم الحبيبي ومعدل الجذر التربيعي لخشونة السطح من خلال صور مجهرية ثنائية الأبعاد2D و ثلاثية الأبعاد3D.

تبين الأشكال 8,7,6 صور مجهر القوة الذرية وتوزيعها التراكمي الحبيبي لـ AuNPs المحضرة عند طول موجي 1064=رح)

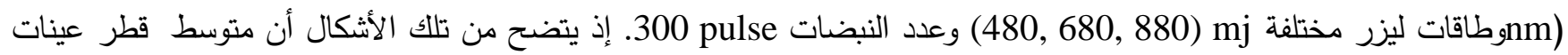
(57.89, 49.74, 25.78)nm AuNP المجهرية (ثنائية الأبعاد) أن التدرج اللوني ذو اللون الداكن يمثل الحجم الاصغر للجسيمات النانوية واللون الفاتح يمثل الحجم الاكبر للجسيمات النانوية. كذلك أظهرت الأشكال المذكورة أنفا أن متوسط قطر الجسيمات النانوية يتتاقص بزيادة طاقة الليزر النبضي وذلك بسبب ان عملية الاستئصال كانت مصحوبة بذوبان السطح المستهدف مع تبخر اقل وحدوث امتصاص تلقائي لفوتون الليزر الساقط من قبل الجسيمات

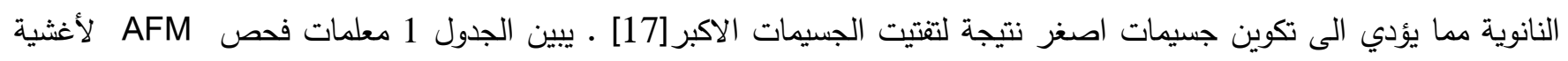
AuNPs تعرف الخشونة على انها الفرق بين اعلى قمة واوطأ قمة للجسيم النانوي) لعينات AuNPs الى nm (1.84, 4.44, 6.19) بزيادة طاقة 
نبضة الليزر (480, 680, 880) على التوالي. إن زيادة طاقة نبضة الليزر تسمح للحبيبات الصغيرة بأن تتجمع (agglomerated)

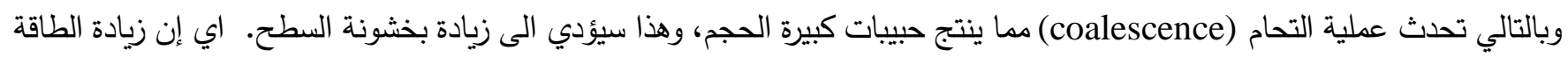
أدت الى تقليل حجم الجسيمات النانوية وفي نس الوقت أصبحت الحبيبات ذات أحجام الدختلفة.
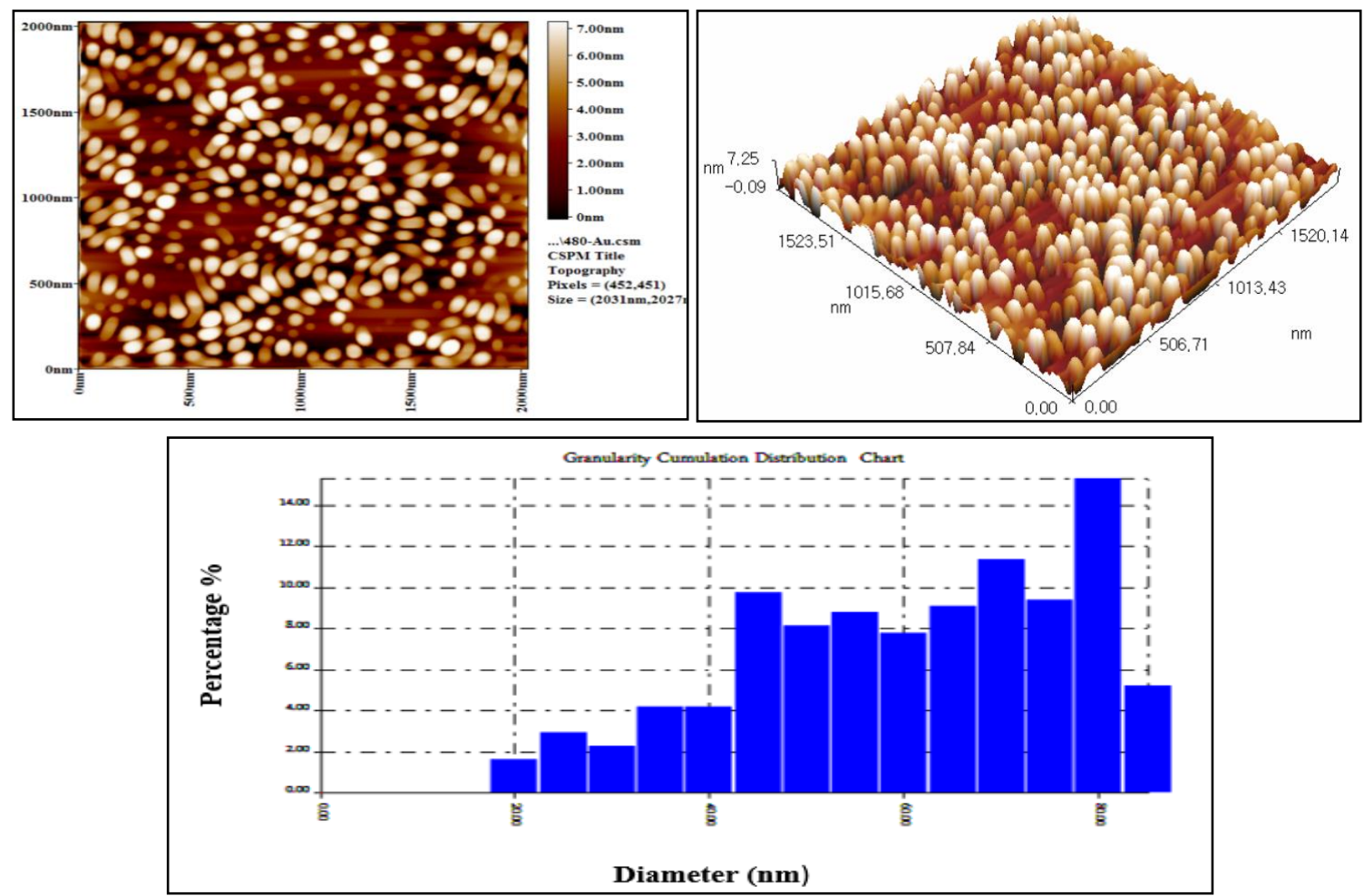

الشكل 6. صور ثنائية وثلاثية الأبعاد لفحص مجهر القوة الذربة (AFM) مع مخطط التوزيع لغشاء جسيمات الذهب النانوية عند طاقة الليزر النبضي (480 mj). 
Journal of Education and Science (ISSN 1812-125X), Vol: 30, No: 4, 2021 (69-82)

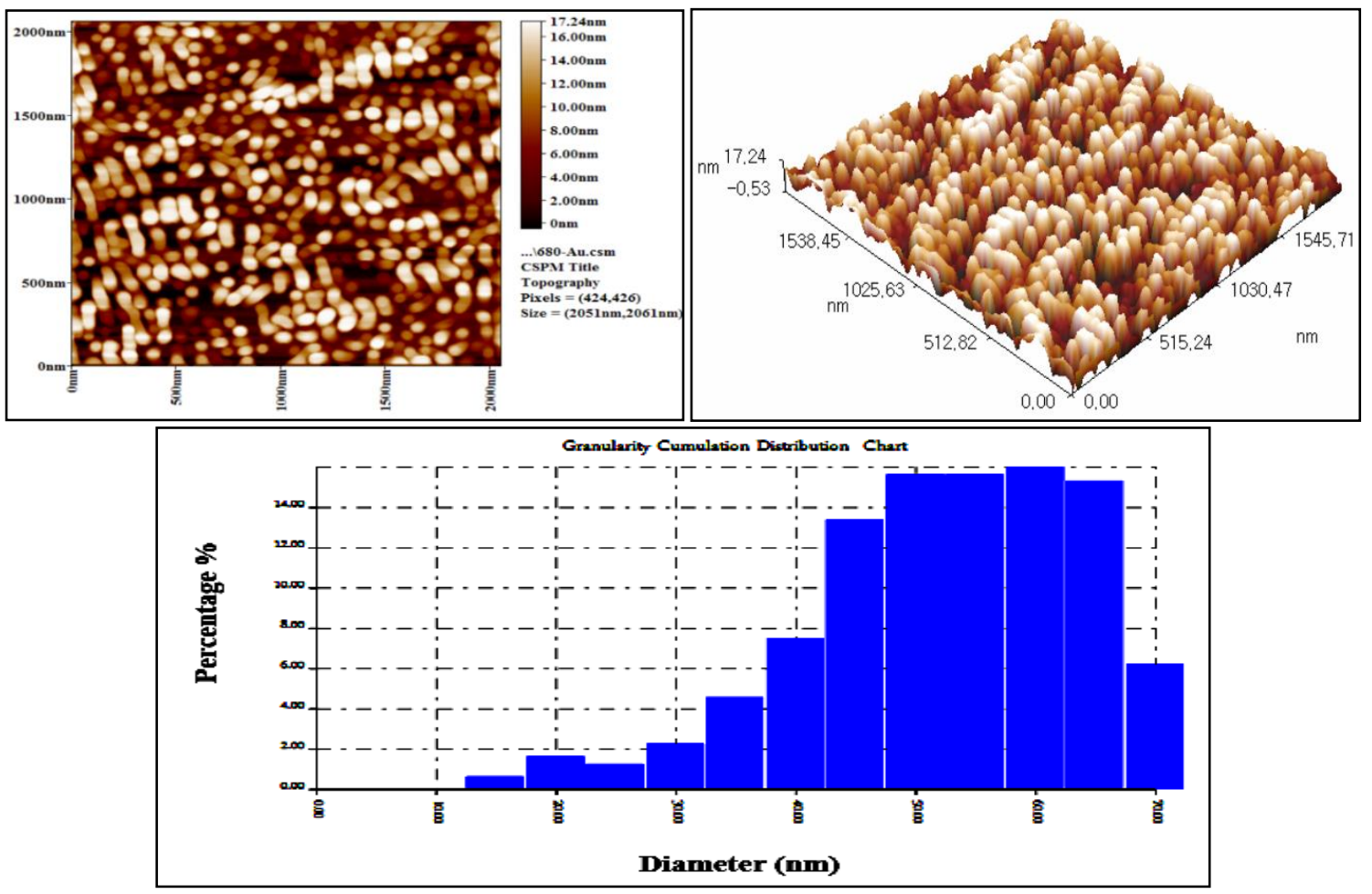

الشكل 7. صور ثنائية وثلاثية الأبعاد لفحص مجهر القوة الذرية (AFM) مع مخطط التوزيع لغشاء جسيمات الذهب النانوية عند طاقة الليزر النبضي (680 mj). 

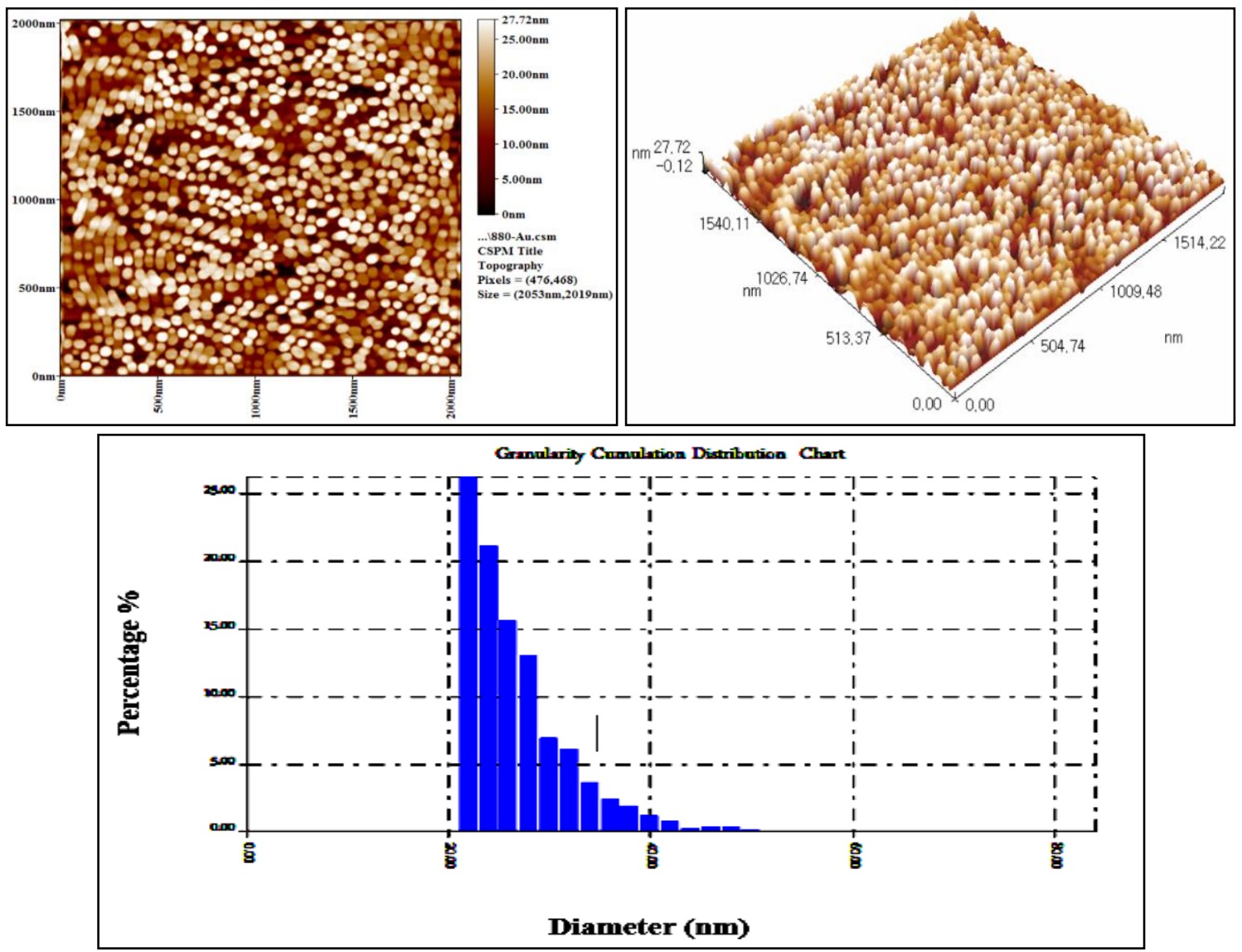

الثكل 8. صور ثنائية وثلاثية الأبعاد لفحص مجهر القوة الذرية (AFM) مع مخطط التوزيع لغشاء جسيمات الذهب النانوية عند طاقة الليزر النبضي (880 mj).

الجدول 1. معلمات فحص AFM لأغشية AuNPs بأختلاف طاقة نبضة الليزر.

\begin{tabular}{|c|c|c|c|c|}
\hline \multirow{3}{*}{ Bulk } & $\begin{array}{c}\text { Laser } \\
\text { Energy(mj) }\end{array}$ & $\begin{array}{c}\text { Avg. Diameter } \\
(\mathrm{nm})\end{array}$ & $\begin{array}{c}\text { Avg. } \\
\text { Roughness } \\
(\mathrm{nm})\end{array}$ & $\begin{array}{c}\text { Root Mean Square } \\
(\mathrm{nm})\end{array}$ \\
\hline \multirow{3}{*}{$\mathrm{Au}$} & 480 & 57.89 & 1.84 & 2.12 \\
\cline { 2 - 5 } & 680 & 49.74 & 4.44 & 5.13 \\
\cline { 2 - 5 } & 880 & 25.78 & 6.19 & 7.27 \\
\hline
\end{tabular}

X-Ray Diffraction Investigation ثالثآ: حيود الاثعة العينية

XRD ( تمت دراسة الخصائص التركيبية للاغشية الرقيقة المحضرة من المحلول النانوي بواسطة حيود الأشعة السينية باستخدام

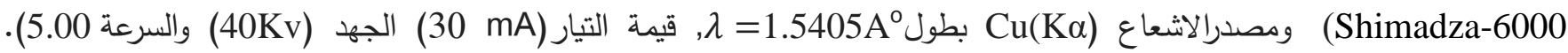
تباينت زاوية المسح الضوئي $2 \Theta$ بدى (1deg/min) والكمي للمركبات البلورية كما تم وصف مبدأ حيود هذه الأثعة بواسطة قانون براك . 
أُجري تحليل XuNPs لتحديد توزيع الطور وتبلور الجسيمات النانوية المركبة لمعرفة أنماط حيود الأشعة السينية لعينة

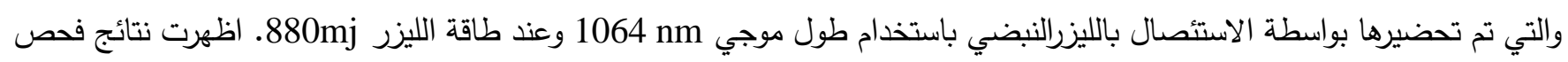

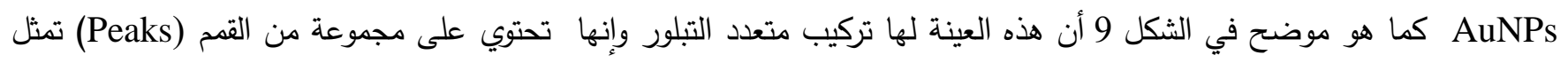

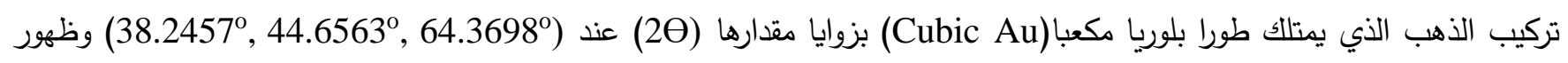
مستويات بلورية عند تلك القمم وهي (220)، (200)، (111) على التوالي.تم حساب الدسافات البينية للمستويات الذربية للتلركيب البلوري (dhkl) حسب قانون براك للحيود

$2 d_{h k l} \sin \theta=n \lambda$

حيث ان dhkl المسافة البينية بين المستويات البلورية، $\theta$ زاوية سقوط الاشعة السينية، n عدد صحيح يمثل رتبة التداخل .وتم تقدير متوسط الاحجام البلورية للجسيمات النانوية (C.S.) من صيغة ديباي شرر المبينة ادناه:

$D_{a v}=\frac{K \lambda}{\beta \cos \theta}$

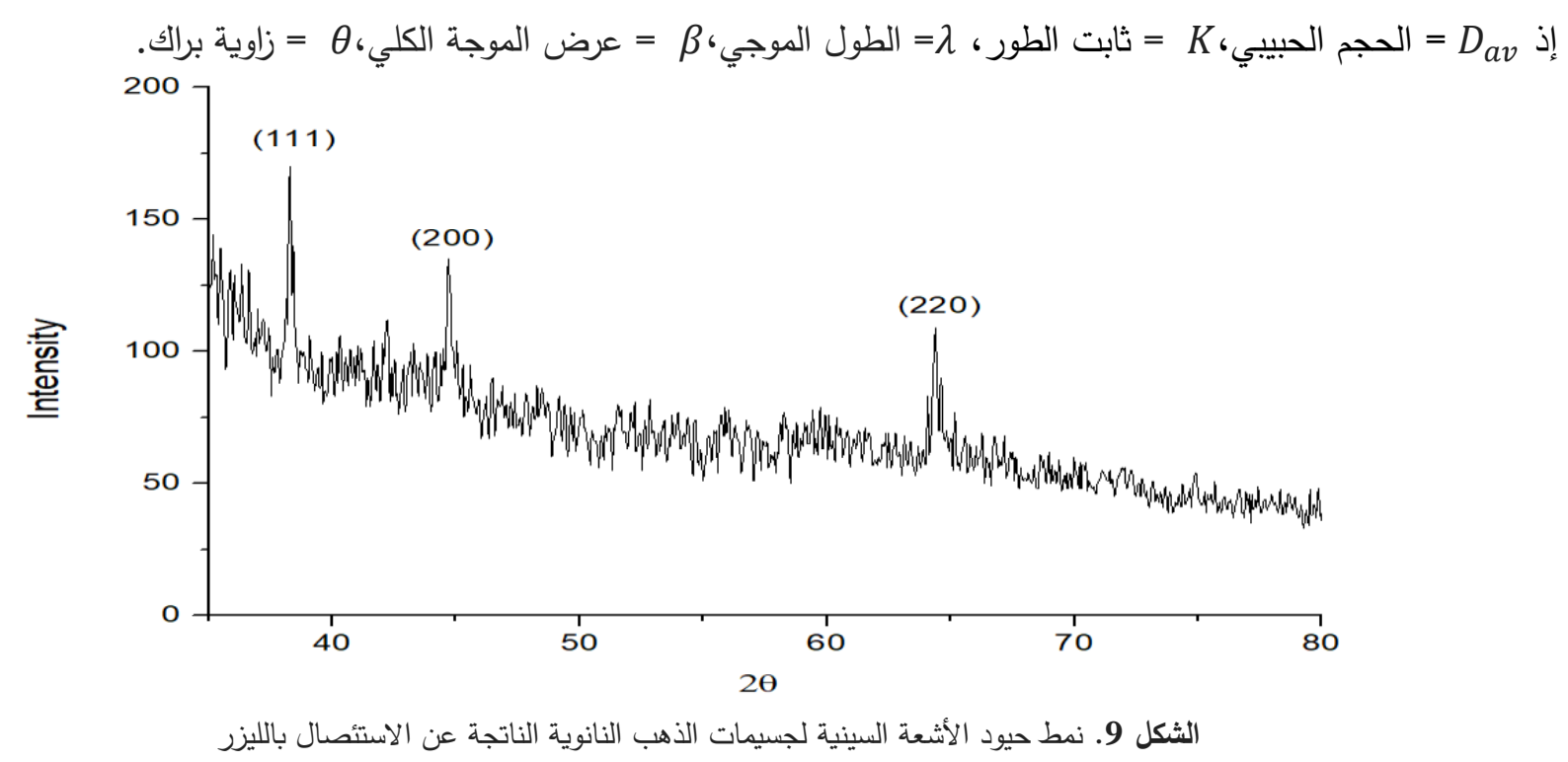
عند الطاقة 880 mj

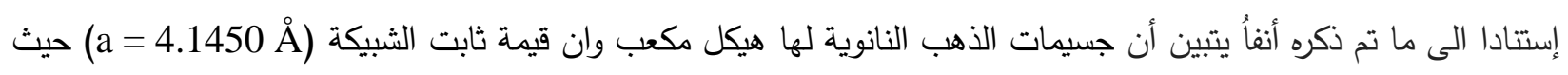

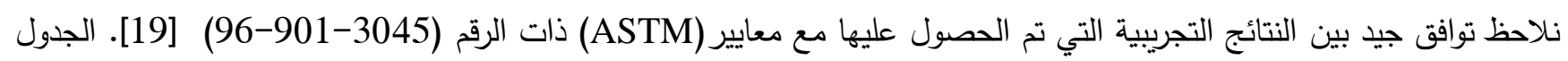

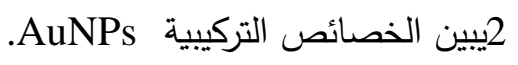

الجدول 2. الخصائص التركيبية الناتجة من فحص XRD.

\begin{tabular}{|c|c|c|c|c|c|c|c|c|}
\hline Bluk & $2 \theta$ (Deg.) & $\begin{array}{c}\text { FWHM } \\
\text { (Deg.) }\end{array}$ & $\begin{array}{c}\mathrm{d}_{\mathrm{hkl}} \\
\operatorname{Exp} .(\AA)\end{array}$ & C.S $(\mathrm{nm})$ & Phase & hkl & Card No. & $\begin{array}{l}\text { Avg. } \\
\text { C.S } \\
(\mathrm{nm})\end{array}$ \\
\hline \multirow{3}{*}{$\mathrm{Au}$} & 38.4257 & 0.1968 & 2.3408 & 42.7 & Cubic & (111) & \multirow{3}{*}{ 96-901-3045 } & \multirow{3}{*}{36.67} \\
\hline & 44.6563 & 0.2952 & 2.0276 & 29.1 & Cubic & (200) & & \\
\hline & 64.3698 & 0.2460 & 1.4462 & 38.2 & Cubic & (220) & & \\
\hline
\end{tabular}




\section{Scanning Electron Microscopy for Nanoparticles}

رابعآ: المجهر الاككتروني الماستح للجسيمات النانوية

إن الغرض من هذا الفحص هو تحليل الخصائص الهيكلية والمورفولوجية لسطوح أغشية العينات للجسيمات النانوية المحضرة بعد

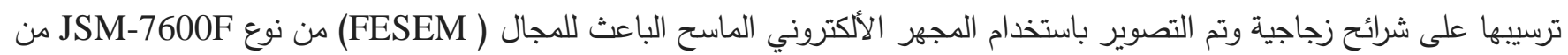

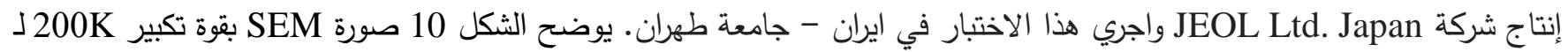

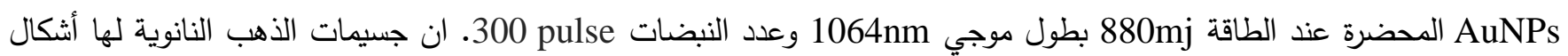
كروية تقريباً وتتتوع في أقطارها من بضعة نانومتر إلى 58 نانومتر .

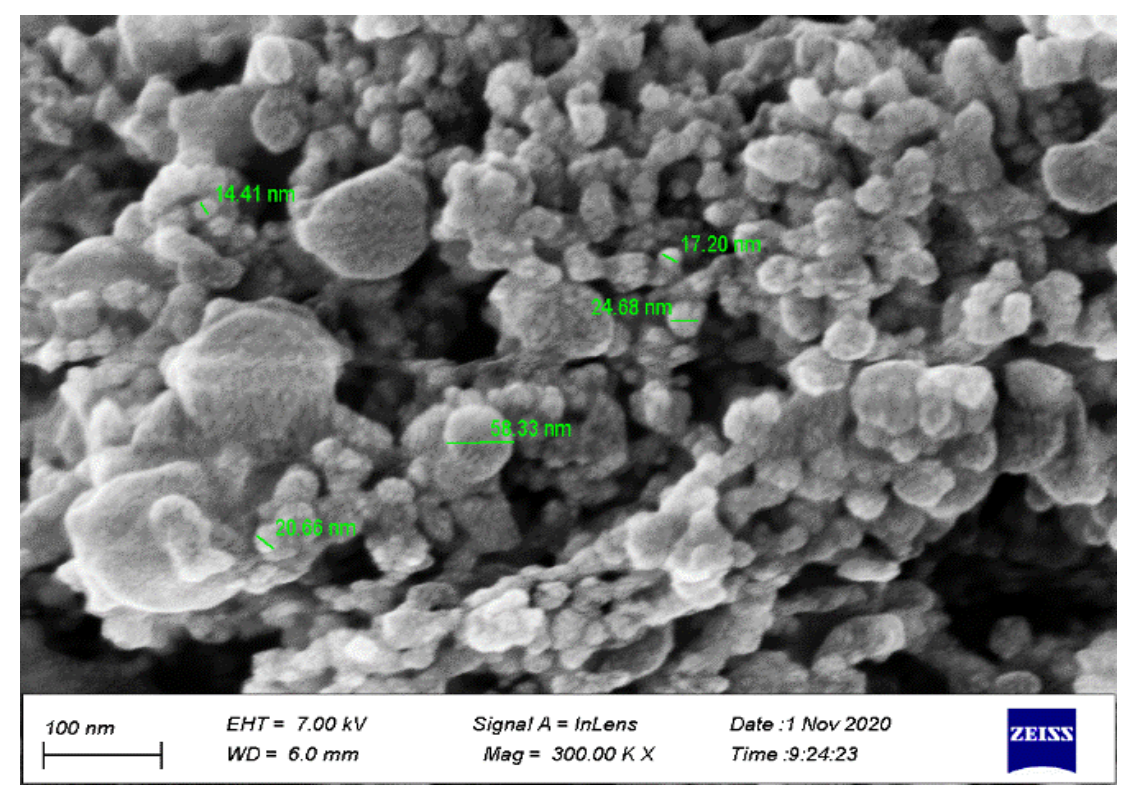

الثكل 10. صورة المجر الألكتروني الماسح الباعث للمجالFESEM لجسيمات AuNPs

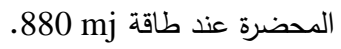

الاستنتاجات

1- يزداد تركيز المحلول لجسيمات الذهب النانوية (عدد الجسيمات المستأصلة ) بزيادة طاقة نبضة الليزر •

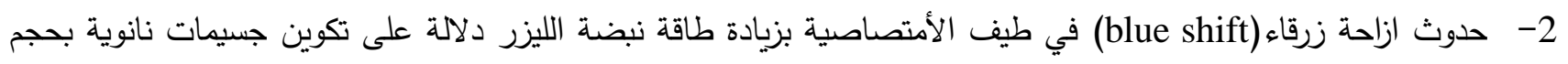

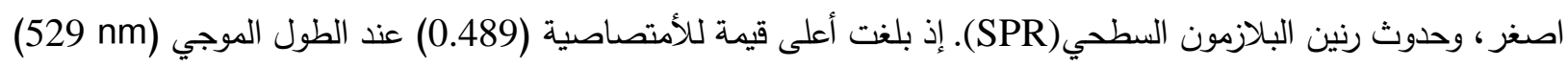
وطاقة نبضة الليزر (880 mj).

3- تقل النفاذية بزيادة طاقة الليزر الملسط بسبب زيادة عدد الجسيمات الماصة للاشعاع الكهرومغناطيسي. 4- أظهرت نتائج فحص AuNPs نقصان متوسط حجم الجسيمات النانوية مع زيادة الطاقة حيث كانت قيم متوسط القطر nm (57.89, 49.47, 25.78) (480, 680, 880) mj عند الطاقات التوالي.

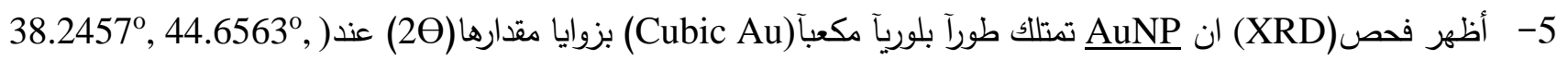

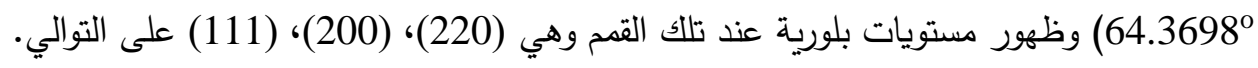
6- تبين من خلال تحليل الخصائص الهيكلية والمورفولوجية لأغشية AuNP المحضرة باستخدام المجهر الالكتروني الماسح (SEM) تمتلك اشكال كروية تقريبآ وتتنوع في اقطارها من بضعة نانومتر الى 58 nm 


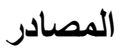

[1] K. Alaqad and T. A. Saleh, "Gold and silver nanoparticles: synthesis methods, characterization routes and applications towards drugs," J. Environ. Anal. Toxicol, vol. 6, pp. 525-2161, 2016, doi: 10.4172/2161-0525.1000384.

[2] M. Ahmeda, N. Ahmida, and A. Ahmeida, "Introduction to nanotechnology: definition, terms, occurrence and applications in environment," Libyan International Medical University Journal, vol. 2, p. 12, 2017, doi: 10.21502/limuj.003.02.2017.

[3] K. D. Sattler, Handbook of nanophysics: nanoparticles and quantum dots: CRC press, Taylor \& Francis Group, LLC, 2011.

[4] A. J. Aswad, S. J. Fathi, and R. M. S. Al-haddad, "Study optical and structural propertiesof copper oxide nanoparticles prepared by pulse laser ablation technology in (LC/MS) water,", Kirkuk University Journal /Scientific Studies (KUJSS), vol.12, Issue 1, January 2017, ISSN 1992 - 0849.

[5] F. A. Mytlak, "Synthesis and characterization of Au nanoparticles for nanomedicine application," Iraqi Journal of Physics (IJP), vol. 15, pp. 109-116, 2017.

[6] K. Sugioka, M. Meunier, and A. Piqué, Laser precision microfabrication: Springer Series in Materials Science, vol. 135, 2010, doi 10.1007/978-3-642-10523-4_2.

[7] N. Kumar, S. Dash, A. Tyagi, and B. Raj, "Dynamics of plasma expansion in the pulsed laser material interaction," Sadhana, vol. 35, pp. 493-511, 2010.

[8] R. Bernath, C. G. Brown, J. Aspiotis, M. Fisher, M. Richardson, "Shock-wave generation in transparent media from ultra-fast lasers," Proc. SPIE 6219, Enabling Technologies and Design of Nonlethal Weapons, 62190A (26 May 2006); doi: 10.1117/12.663818.

[9] S. Link, C. Burda, Z. L. Wang, and M. A. El-Sayed, "Electron dynamics in gold and gold-silver alloy nanoparticles: The influence of a nonequilibrium electron distribution and the size dependence of the electron-phonon relaxation," The Journal of chemical physics, vol. 111, pp. 1255-1264, 1999.

[10] S. J. Hill, "Inductively coupled plasma spectrometry and its applications", 2nd Edition, WileyBlackwell, 448 pages, November 2007.

[11] J. A. Grant-Jacob, S. J. Beecher, T. L. Parsonage, P. Hua, J. I. Mackenzie, D. P. Shepherd, et al., "An 11.5 W Yb: YAG planar waveguide laser fabricated via pulsed laser deposition," Optical Materials Express, vol. 6, pp. 91-96, 2016.

[12] M. A. K. Abdelhalim, M. M. Mady, and M. M. Ghannam, "Physical properties of different gold nanoparticles: ultraviolet-visible and fluorescence measurements," J. Nanomed Nanotechol, vol. 3, pp. 178-194, 2012.

[13] R. K. I. AL-Ageedie, "Surface Plasmon Resonance of Gold and Silver Nanoparticles for Biomedical Physics Applications," PhD Thesis, College of Science, University of Diyala, Iraq., 2019. 
[14] E. Y. Lukianova-Hleb, D. S. Wagner, M. K. Brenner, and D. O. Lapotko, "Cell-specific transmembrane injection of molecular cargo with gold nanoparticle-generated transient plasmonic nanobubbles," Biomaterials, vol. 33, pp. 5441-5450, 2012.

[15] H. K. Ghazi, "An Investigation Linear and Nonlinear Optical Properties of PVA Doped with Ag NPs Created by Nd-YAG Pulse Laser," MSc.Thesis, College of Education, University of AlQadisiayh,Iraq, 2018.

[16] V. Subha, S. Kirubanandan, and S. Renganathan, "Green synthesis of silver nanoparticles from a novel medicinal plant source roots extract of Mukia maderaspatana," Colloid and Surface Science, vol. 1, pp. 14-17, 2016.

[17] M. C. Sportelli, M. Izzi, A. Volpe, M. Clemente, R. A. Picca, A. Ancona, et al., "The pros and cons of the use of laser ablation synthesis for the production of silver nano-antimicrobials," Antibiotics, vol. 7, p. 67, 2018.

[18] A. A. Manty, "Producing Metal oxides for Nano-particals by Laser Induced Plasma and Studying Some physical Properties," MSc.Thesis, College of Science, University of Wasit, Iraq., 2019.

[19] I.-K. Suh, H. Ohta, and Y. Waseda, "High-temperature thermal expansion of six metallic elements measured by dilatation method and X-ray diffraction," Journal of Materials Science, vol. 23, pp. 757-760, 1988. 